\title{
Effect of Intravenous Glucagon on the Survival of Rats after Acute Occlusive Mesenteric Ischemia
}

\author{
JaCk L. Cronenwett, M.D., ${ }^{1}$ Medhat Ayad, M.D., And Andris Kazmers, M.D. \\ Department of Surgery, University of Michigan, and Veterans Administration Medical Center, \\ Ann Arbor, Michigan 48109; and Department of Surgery, Dartmouth-Hitchcock \\ Medical Center, Hanover, New Hampshire 03756
}

Presented at the Annual Meeting of the Association for Academic Surgery,

San Antonio, Texas, October 31-November 3, 1984

\begin{abstract}
The purpose of this study was to determine the optimal timing of intravenous glucagon infusion for the treatment of acute occlusive mesenteric ischemia. The superior mesenteric artery (SMA) was occluded for $85 \mathrm{~min}$ in 106 Sprague-Dawley anesthetized rats. The animals were divided into 12 treatment groups according to the timing of glucagon and saline administration, and survival was measured to $48 \mathrm{hr}$. Without treatment, all rats died within $24 \mathrm{hr}$. Intravenous saline ( $10 \mathrm{ml} / \mathrm{kg} / \mathrm{hr}$ ) for $2 \mathrm{hr}$ did not significantly improve 48 -hr survival (17-33\%). Glucagon $(1.6 \mu \mathrm{g} / \mathrm{kg} / \mathrm{min}$ iv) plus saline (10 ml/kg/hr iv) for $2 \mathrm{hr}$ after SMA occlusion significantly improved survival from 33\% (saline control) to $83 \%(P<0.02)$. The same treatment begun $1 \mathrm{hr}$ before SMA release (during ischemia) did not significantly improve survival $(33 \%$ at $48 \mathrm{hr}$ ). Glucagon infusion during occlusive mesenteric ischemia was detrimental when added to effective postischemia treatment, reducing survival from 83 to $33 \%(P<0.02)$. Adequate saline infusion was required for glucagon efficacy after ischemia, as shown by an intermediate 48 -hr survival of $50 \%$ when only maintenance saline $(1.5 \mathrm{ml} / \mathrm{kg} / \mathrm{hr})$ was given. These data suggest that glucagon therapy should be delayed until after operative release of an acute SMA occlusion and should be accompanied by vigorous volume expansion. (c) 1985 Academic Press, Inc.
\end{abstract}

\section{INTRODUCTION}

Acute mesenteric ischemia due to embolism or thrombosis is associated with high mortality [15]. To improve the outcome of these patients, selective mesenteric vasodilator therapy has been advocated as an adjunct to standard surgical treatment $[1,3]$. Glucagon is a potent mesenteric vasodilator that has been shown to effectively increase normal superior mesenteric artery (SMA) blood flow even when administered intravenously $[7,8$, 14]. Using a rat SMA ischemia model, Kazmers et al. demonstrated prolonged survival after intravenous glucagon given both during and after the ischemic period [9]. In a canine model of occlusive mesenteric ischemia, however, we demonstrated that glucagon did

\footnotetext{
1 To whom correspondence and reprint requests should be addressed: Department of Surgery, Dartmouth-Hitchcock Medical Center, 2 Maynard Street, Hanover, NH 03756 .
}

not improve ileal blood flow until after release of tourniquet ischemia, and, in fact, was detrimental during ischemia [16]. Based on these studies, we hypothesized that the beneficial effects of glucagon treatment might be due primarily to relief of mesenteric vasoconstriction that occurs after intestinal ischemia, rather than to beneficial effects during SMA occlusion. The present study was designed to test this hypothesis by examining the survival of rats after intravenous glucagon therapy given at various times in relation to occlusive mesenteric ischemia.

\section{METHODS}

Male Sprague-Dawley rats weighing 400 $\pm 12 \mathrm{~g}$ (mean $\pm 1 \mathrm{SD}$, range: $370-430 \mathrm{~g}$ ) that had been allowed free access to food and water were anesthetized with chloral hydrate $(0.5 \mathrm{~g} / \mathrm{kg} \mathrm{ip})$. Using clean surgical technique, one jugular vein was cannulated with PE 50 tubing to allow subsequent intra- 


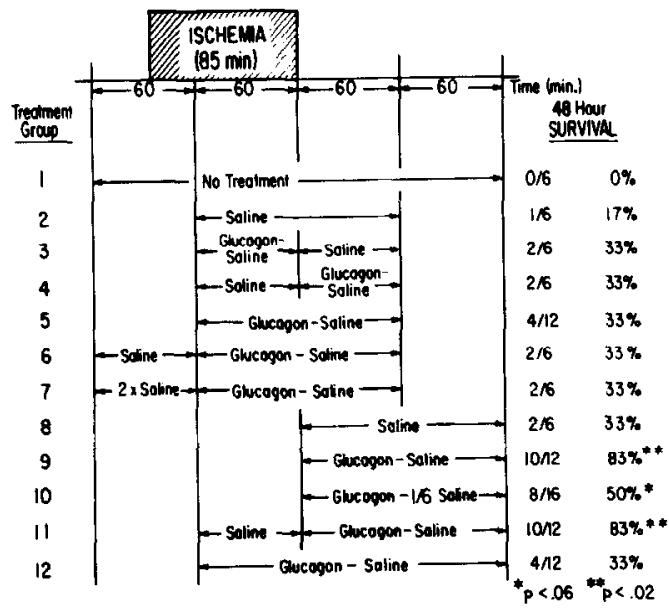

FIG. 1. Experimental protocol illustrating the 12 treatment groups and their 48-hr survival. Significant differences are indicated from other groups $\left(x^{2}\right)$.

venous infusion. A midline laparotomy was performed, and the cranial mesenteric artery (SMA) was exposed at its origin from the aorta. Mesenteric ischemia was then produced by 85 min of SMA occlusion using a microserrefine vascular clamp applied at the SMA origin. After clamp removal, intestinal reperfusion occurred, as evidenced by rapid return of color and arterial pulsation in the mesentery. The $85-\mathrm{min}$ duration of ischemia was selected after pilot studies in our laboratory demonstrated that this was the minimum time required to produce $100 \%$ mortality at $48 \mathrm{hr}$ with no treatment. During the time of SMA occlusion, the abdomen was temporarily reapproximated to prevent evaporative fluid loss and intestinal desiccation. Following the ischemic period and a subsequent 2 -hr treatment interval, the jugular vein catheter was removed and the cervical and abdominal incisions closed with silk suture. The animals were then observed at $4,8,16,24$, and 48 $\mathrm{hr}$, and their survival noted. Previous data and pilot studies from our laboratory demonstrated that all rats surviving $48 \mathrm{hr}$ after intestinal ischemia had prolonged survival [9]. Therefore, 48-hr survival was judged sufficient to predict long-term survival in this study. Selected animals underwent autopsy with light microscopic examination of their small intestine.

Rats received either no treatment, intravenous normal saline in varying dosage, or intravenous normal saline plus glucagon, at varying times with respect to intestinal ischemia (Fig. 1). Nominal intravenous infusion rates were based on an expected weight of $400 \mathrm{~g}$ for all rats. Glucagon was given at 1.60 $\pm .05 \mu \mathrm{g} / \mathrm{kg} / \mathrm{min}$ (mean $\pm 1 \mathrm{SD}$ ), with a range of 1.49 to $1.71 \mu \mathrm{g} / \mathrm{kg} / \mathrm{min}$ due to individual rat weight variations. Normal saline was infused at $10.2 \pm 0.9 \mathrm{ml} / \mathrm{kg} / \mathrm{hr}$ (mean $\pm 1 \mathrm{SD}$ ), with a range of 9.3 to $14.0 \mathrm{ml} / \mathrm{kg} / \mathrm{hr}$ in individual rats. Among the 12 treatment groups, the range of mean rat weight, glucagon dose, and saline dose was 392 to $405 \mathrm{~g}$, 1.50 to $1.60 \mu \mathrm{g} / \mathrm{kg} / \mathrm{min}$ and 9.9 to $10.1 \mathrm{ml} /$ $\mathrm{kg} / \mathrm{hr}$, respectively.

A total of 106 rats were divided into the following 12 treatment groups:

\footnotetext{
Group 1 No treatment $(n=6)$

Group 2 Normal saline for $60 \mathrm{~min}$ before and $60 \mathrm{~min}$ after SMA declamping $(n=6)$

Group 3 Glucagon in saline for $60 \mathrm{~min}$ before, and saline alone for $60 \mathrm{~min}$ after SMA declamping $(n=6)$

Group 4 Saline for $60 \mathrm{~min}$ before, and glucagon in saline for $60 \mathrm{~min}$ after SMA declamping $(n=6)$

Group 5 Glucagon in saline both $60 \mathrm{~min}$ before and after SMA declamping $(n=12)$

Group 6 Saline for $60 \mathrm{~min}$ beginning $35 \mathrm{~min}$ before SMA clamping, followed by glucagon in saline for $60 \mathrm{~min}$ before and $60 \mathrm{~min}$ after SMA declamping $(n=6)$
}

Group 7 Saline at $20 \mathrm{ml} / \mathrm{kg} / \mathrm{hr}$ ( $2 \times$ normal dose) beginning $35 \mathrm{~min}$ before SMA clamping, followed by glucagon in saline for $60 \mathrm{~min}$ before and $60 \mathrm{~min}$ after SMA declamping $(n=6)$ 
Group 8 Saline alone for 120 min after SMA declamping $(n=6)$

Group 9 Glucagon in saline for $120 \mathrm{~min}$ after SMA declamping $(n=12)$

Group 10 Glucagon in $1.5 \mathrm{ml} / \mathrm{kg} / \mathrm{hr}$ saline ( $1 / 6$ normal dose) for $120 \mathrm{~min}$ after SMA declamping $(n=16)$

Group 11 Saline for $60 \mathrm{~min}$ before, and glucagon in saline for $120 \mathrm{~min}$ after SMA declamping $(n=12)$

Group 12 Glucagon in saline for $60 \mathrm{~min}$ before and $120 \mathrm{~min}$ after SMA declamping $(n=12)$

Data were computerized and life table survival (Kaplan-Meier product-limit) was compared among groups with the MantelCox nonparametric test, as well as by $\chi^{2}$ analysis at the 48-hr time point [5].

\section{RESULTS}

Survival at $48 \mathrm{hr}$ for the 12 treatment groups is summarized in Fig. 1. Without treatment, $85 \mathrm{~min}$ of SMA occlusion was $100 \%$ fatal, with $0 / 6$ rats surviving $24 \mathrm{hr}$ (Group 1). Vigorous saline replacement (10 $\mathrm{ml} / \mathrm{kg} / \mathrm{hr}$ ), given $1 \mathrm{hr}$ beforc and $1 \mathrm{hr}$ after SMA declamping, did not statistically improve survival, with $1 / 6$ rats surviving $48 \mathrm{hr}$ (17\%, Group 2, Fig. 2). The addition of intravenous glucagon at $1.6 \mu \mathrm{g} / \mathrm{kg} / \mathrm{min}$ to this saline treatment for $1 \mathrm{hr}$ before SMA declamping also did not significantly improve survival, with $2 / 6$ rats surviving $48 \mathrm{hr}$ (33\%, Group 3). Delaying this 1-hr glucagon infusion until after mesenteric ischemia resulted in the same $33 \%$ survival at $48 \mathrm{hr}(2 / 6$ rats, Group 4). Although early survival (up to 24

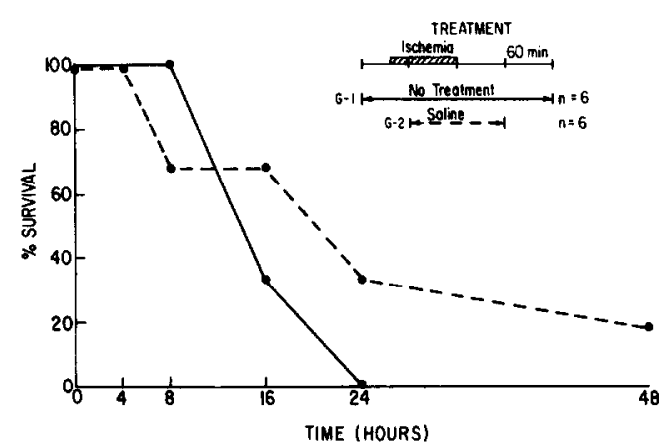

FIG, 2. Saline treatment $(10 \mathrm{ml} / \mathrm{kg} / \mathrm{hr})$ during and after mesenteric ischemia (G-2) did not significantly improve survival compared with no treatment (G-1). hr) appeared to be somewhat improved by this delay in treatment (Fig. 3), overall life table survival was not statistically different. Increasing the duration of glucagon infusion to $2 \mathrm{hr}(1 \mathrm{hr}$ before and $1 \mathrm{hr}$ after SMA declamping) improved intermediate (16 and $24 \mathrm{hr}$ ) survival, resulting in life table survival of these Group 5 rats that was nearly significantly greater than saline treated Group 2 rats, with $P=0.15$ (Mantel-Cox). By $48 \mathrm{hr}$, however, the survival of Group 5 rats, treated with glucagon both during and after ischemia, was $33 \%$, not significantly improved from the other treatment groups.

To ensure that potential efficacy of glucagon treatment was not impeded by inadequate saline resuscitation, supplementary saline pretreatment was added to the glucagonsaline infusion previously shown to be nearly significant in Group 5 animals. In Group 6, saline was infused at $10 \mathrm{ml} / \mathrm{kg} / \mathrm{hr}$ for $1 \mathrm{hr}$ before glucagon treatment, beginning $35 \mathrm{~min}$ before ischemia, and in Group 7, twice this

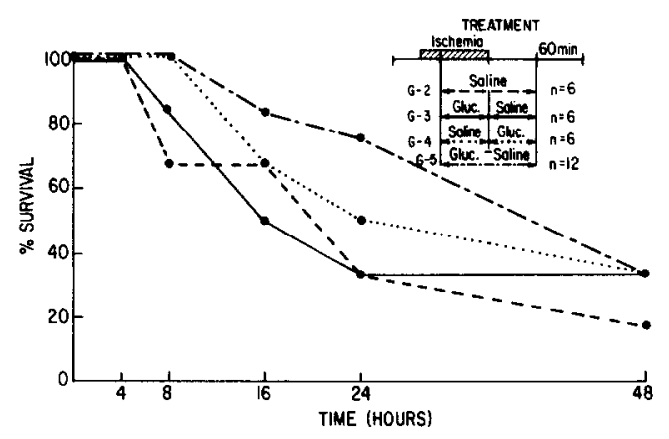

FIG. 3. Glucagon treatment $(1.6 \mu \mathrm{g} / \mathrm{kg} / \mathrm{min})$ during (G-3) or after (G-4) ischemia did not improve survival over saline treated alone (G-2). Glucagon both during and after ischemia (G-5) nearly improved survival over saline alone $(P=0.15$ ). 
volume of supplementary saline was infused during the same interval. Neither of these groups demonstrated improved survival, however, either at $48 \mathrm{hr}$ (33\% in all Groups) or earlier, by life table analysis (Fig. 4).

Next, the 2-hr glucagon-saline infusion (Group 5) that almost significantly improved survival when given during and after ischemia was delayed and given for $2 \mathrm{hr}$ after ischemia (Group 9). This treatment resulted in a significant improvement of 48-hr survival, from 33 to $83 \%\left(P<0.02, \chi^{2}\right)$ and a statistically significant improvement in life table survival (Group 9 vs Group 5, $P<0.02$, MantelCox, Fig. 5). As a control, saline infusion alone was given for $2 \mathrm{hr}$ after ischemia, but did not improve early or 48-hr survival (33\%, Group 8, Fig. 5). Glucagon-saline infusion for $2 \mathrm{hr}$ after ischemia (Group 9) significantly improved survival compared with this saline control (Group 8), both at $48 \mathrm{hr}(83 \%$ vs $\left.33 \%, P<0.02, \chi^{2}\right)$ and by life table analysis $(P<0.02$, Mantel-Cox $)$.

Improved survival seen after postischemia glucagon infusion was dependent on adequate simultaneous saline replacement. When only 1.5 instead of $10 \mathrm{ml} / \mathrm{kg} / \mathrm{hr}$ of saline was administered with glucagon, 48-hr survival was reduced to $50 \%$ (8/16 rats, Group 10$)$. This survival was intermediate to that seen with full-dose saline replacement (Group 9) and saline alone (Group 8, Fig. 6). By life table analysis, the survival for rats treated

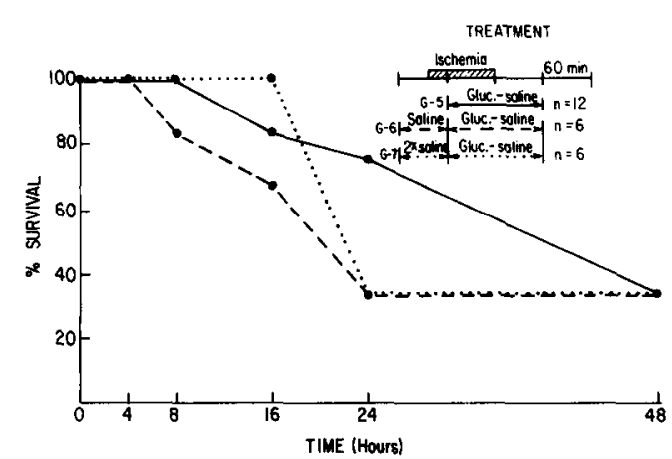

FIG. 4. Saline preinfusion, before glucagon treatment, at $10 \mathrm{ml} / \mathrm{kg} / \mathrm{hr}(\mathrm{G}-6)$ or $20 \mathrm{ml} / \mathrm{kg} / \mathrm{hr}(\mathrm{G}-7)$, did nol significantly improve survival compared to glucagonsaline treatment alone (G-5).

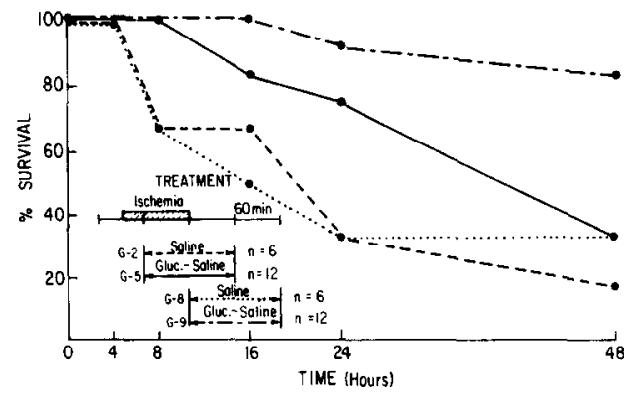

FIG. 5. Saline treatment for $120 \mathrm{~min}$ after ischemia (G-8) did not alter survival from saline treatment for 60 min during and after ischemia (G-2). Glucagon treatment delayed until after ischemia (G-9), however, significantly improved survival compared with saline alone (G-8, $P$ $<0.02$ ) or glucagon during and after ischemia (G-5, $P$ $<0.02$ ).

with glucagon and $1.5 \mathrm{ml} / \mathrm{kg} / \mathrm{hr}$ of saline appeared better than rats treated with $10 \mathrm{ml} /$ $\mathrm{kg} / \mathrm{hr}$ of saline alone $(P=0.024)$, but worse than rats treated with glucagon and 10 $\mathrm{ml} / \mathrm{kg} / \mathrm{hr}$ of saline (Fig. $6, P=0.065$, Mantel-Cox).

To further assess the value of glucagon infusion during occlusive mesenteric ischemia, two additional treatment groups were compared. As a control, 12 rats received saline alone for $60 \mathrm{~min}$ during ischemia, followed by glucagon-saline treatment for $120 \mathrm{~min}$ after ischemia (Group 11). This treatment resulted in the same 48-hr survival of $83 \%$ previously seen in rats treated with only postischemic glucagon-saline (Group 9 ).

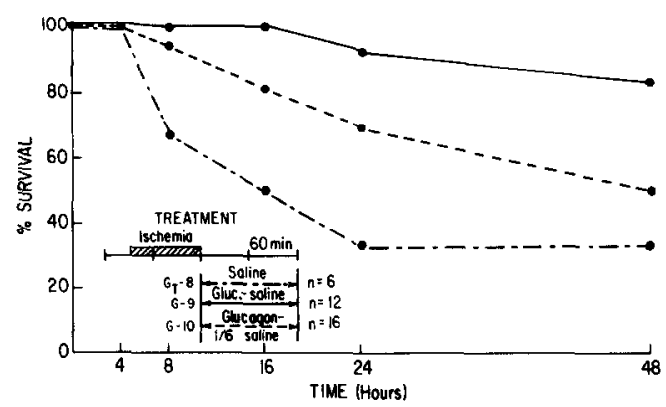

FIG. 6. Glucagon plus saline at $10 \mathrm{ml} / \mathrm{kg} / \mathrm{hr}$ for 120 min after mesenteric ischemia (G-9) significantly improved survival over saline alone (G-8, $P<0.02$ ). Glucagon plus $1.5 \mathrm{ml} / \mathrm{kg} / \mathrm{hr}$ saline (G-10) produced an insignificant improvement in survival (G-8 vs G-10, $P$ $=0.24$; G-9 vs G-10, $P=0.065$ ). 
Glucagon-saline was then infused for $1 \mathrm{hr}$ before and $2 \mathrm{hr}$ after SMA declamping (Group 12). This additional hour of intraischemic glucagon treatment reduced $48-\mathrm{hr}$ survival from $83 \%$ (Group 11 ) to $33 \%$ (4/12 rats), equivalent to saline treatment alone. Life table survival of these groups was significantly different (Fig. 7, $P<0.03$, MantelCox), as was the $33 \%$ vs $83 \% 48$-hr survival $\left(P<0.02, \chi^{2}\right)$.

Autopsy of selected rats expiring prior to $48 \mathrm{hr}$ after mesenteric ischemia demonstrated patchy areas of full-thickness small bowel necrosis, with perforation and often frank purulent peritonitis. Light microscopy of these bowel segments demonstrated ischemic changes ranging from mucosal loss with acute inflammation in relatively preserved areas to full-thickness necrosis with hemorrhagic infarction in advanced ischemia regions. Autopsy of selected animals surviving more than $48 \mathrm{hr}$ after ischemia demonstrated viable intestine with occasional areas of healing ischemic damage, manifested grossly by slight discoloration and microscopically by a chronic inflammatory infiltrate.

\section{DISCUSSION}

The rat mesenteric ischemia model used in this study was a severe one, resulting in $100 \%$ mortality by $24 \mathrm{hr}$ without treatment. Survival after temporary SMA occlusion is sensitive to the exact duration of ischemia, as well as other factors, such as extent of operative manipulation, catheter placement, etc. Pilot studies in our laboratory and a

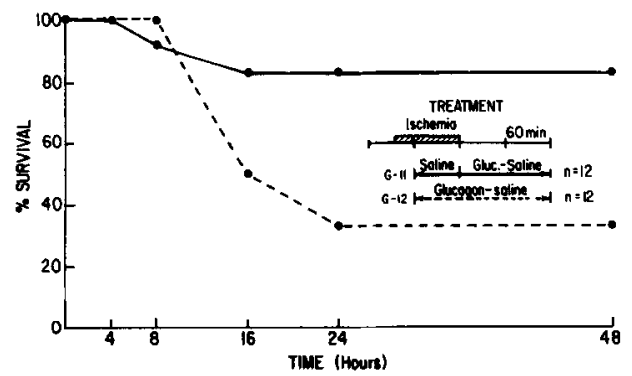

FIG. 7. Glucagon treatment during ischemia (G-12) significantly reduced survival when compared with effective glucagon treatment after ischemia (G-11, $P<0.03$ ). detailed analysis of rat SMA occlusion times by Kazmers et al. resulted in the selection of $85 \mathrm{~min}$ as an appropriate duration for ischemia [9]. Despite the severity of this model, it was able to discriminate effective pharmacologic treatment, as judged by the significant improvement in survival after postischemic glucagon-saline treatment.

Adequate saline resuscitation was necessary for effective glucagon therapy in our study. Mesenteric ischemia is known to be associated with volume shifts from the intravascular compartment to the intestinal wall and lumen, resulting in the potential for circulatory collapse upon vasodilator treatment $[4,12]$. The volume of saline resuscitation selected in our study, $10 \mathrm{ml} / \mathrm{kg} / \mathrm{hr}$, represents vigorous replacement therapy and was superior to maintenance infusion of $1.5 \mathrm{ml} / \mathrm{kg} / \mathrm{hr}$ of saline. Our study was not designed, however, to determine the optimal rate of saline replacement, nor were measurements made of vascular volume in these rats. Therefore, in extrapolating these results to clinical therapy, vigorous saline replacement guided by appropriate central monitoring should be applied, rather than any specific infusion guideline implied by these animal results.

Comparison between Groups 11 and 12 in our study demonstrates that glucagon infusion during occlusive ischemia was detrimental if compared to infusion given only after ischemia. This inability of glucagon to improve survival when administered during occlusive ischemia was in sharp contrast to the marked improvement in survival seen when glucagon was withheld until after release of the SMA occlusion. These results support our previous study of canine intestinal blood flow measured during and after SMA tourniquet ischemia [16]. In that study, intravenous glucagon was not able to improve ileal wall flow during occlusive ischemia, and, in fact, reduced collateral blood flow as measured by radiolabeled microspheres. After release of SMA occlusion in those dogs, however, glucagon markedly improved SMA blood flow and restored intestinal oxygen consumption to normal [16]. 
These results support the hypothesis that intravenous glucagon infusion during SMA occlusion is not capable of further vasodilating ischemic areas of intestine that are already maximally vasodilated due to the local response to ischemia. In this situation, the ability of glucagon to vasodilate other (nonischemic) splanchnic regions [14] could result in a detrimental redistribution of splanchnic blood flow, particularly if total flow is limited by reduced vascular volume or marginal cardiac reserve. After relief of occlusive SMA ischemia, however, local mesenteric vasodilation is replaced by a generalized vasoconstriction $[2,16]$. This vasoconstriction, in response to low cardiac output, has been attributed to diminished vascular volume, direct cardiac depressant substances, and other unknown factors $[6,11,12]$. In the mesenteric circulation, it contributes to persistent intestinal ischemia and is therefore detrimental to the organism, assuming that adequate volume has been replaced to prevent cardiovascular collapse if vasodilation were to occur. In the present study, postocclusive glucagon treatment may have improved survival by relieving ischemia that persists after release of SMA occlusion.

The mechanism by which glucagon improved survival after mesenteric ischemia, however, was not specifically addressed in our study. Multiple factors may be involved in addition to the ability of glucagon to cause selective mesenteric vasodilation. Glucagon is known to provide cardiac inotropic and chronotropic support $[10,17]$. This may be important after mesenteric reperfusion, when cardiac depression is known to occur $[4,6$, $11,16]$. Other glucagon actions, however, including its metabolic effects and inhibitory effects on gut and pancreatic secretion [13], may play a role in the effects of glucagon after mesenteric ischemia. Certainly, selective mesenteric vasodilation and cardiac inotropic support make glucagon an attractive agent for treatment of postocclusive mesenteric ischemia, as verified by the results of our study. The effectiveness of intravenously administered glucagon, as opposed to agents requiring selective SMA infusion [1, 3], adds to the potential of glucagon for clinical use.

The results of our current study are at variance with the initial report of Kazmers et al. that glucagon infusion both during and after occlusive mesenteric ischemia improved rat survival [9]. This may relate to the larger volume of saline replacement $(17 \mathrm{ml} / \mathrm{kg} / \mathrm{hr})$ used by Kazmers et al, to differences in the breed and size of rat employed, or to details of the experimental preparation. In the present study, where the timing of glucagon administration was specifically studied, there was clear evidence that optimal results were obtained by delaying this treatment until after the release of SMA occlusion. Caution must be exercised before generalizing this animal study to patient treatment, however, since mesenteric collateral blood flow, intestinal microcirculation, and systemic sympathetic and hormonal responses may differ in humans. Nevertheless, our study indicates that intravenous vasodilator therapy may not be beneficial during occlusive mesenteric ischemia, which should prompt further study of this therapeutic approach.

\section{REFERENCES}

1. Boley, S. J., Feinstein, F. R., Sammartano, R., Brandt, L. J., and Sprayregen, S. New concepts in the management of emboli of the superior mesenteric artery. Surg. Gynecol. Obstet. 153: 561, 1981.

2. Boley, S. J., Regan, J. A., Tunick, P. A., Everhard, M. E., Winslow, P. R., and Veith, F. J. Persistent vasoconstriction-A major factor in non-occlusive mesenteric ischemia. Curr. Top. Surg. Res. 3: 425, 1971.

3. Boley, S. J., Sprayregan, S., Siegelman, S. S., and Veith, F. J. Initial results from an aggressive roentgenological and surgical approach to acute mesenteric ischemia. Surgery 82: 848, 1977.

4. Chiu, C. J., Scott, H. J., and Gurd, F. N. Volume deficit versus toxic absorption: A study of canine shock after mesenteric arterial occlusion Ann. Surg. 175: 479, 1972.

5. Dixon, W. J., Brown, M. B., Engleman, L., Frane, J. W., Hill, M. A., Jeunrick, R. I., and Toporek, J. D. BMDP Statistical Software, Los Angeles: Univ. of California Press, 1983.

6. Haglund, U., Myrvold, H., and Lundgren, O. Cardiac and pulmonary function in regional intestinal shock. Arch. Surg. 113: 963, 1978. 
7. Holliger, C., Radzyner, M., Villiger, A., Anliker, M., and Knoblanch, M. Effects of glucagon, vasoactive intestinal peptide (VIP) and lysine-vasopressine on villous microcirculation and superior mesenteric artery blood flow of the rat. Bibl. Anat. 18: 129, 1979.

8. Kazmers, A., Wright, C. D., Whitehouse, W. M., Jr., Zelenock, G. B., Lindenauer, S. M., and Stanley, J. C. Glucagon and canine mesenteric hemodynamics: Effects on superior mesenteric arteriovenous and nutrient capillary blood flow. J. Surg. Res. 30: 372, 1981.

9. Kazmers, A., Zwolak, R., Appleman, H. D., Whitehouse, W. M., Jr., Wu, S. C. H., Zelenock, G. B., Cronenwett, J. L., Lindenauer, S. M., and Stanley, J. C. Pharmacologic interventions in acute mesenteric ischemia: Improved survival with intravenous glucagon, methylpredisolone, and prostacyclin. J. Vasc. Surg. 1: 472, 1984.

10. Lucchesi, B. R. Cardiac actions of glucagon. Circ. Res. 22: 777, 1968.

11. Lundgren, O., Haglund, U., Isaksson, O., and Abe, $T$. Effects on myocardial contractibility of blood- borne material released from the feline small intestine in simulated shock. Circ. Res. 38: 307, 1976.

12. Marston, A. Causes of death in mesenteric arterial occlusion. I. Local and general effects of devascularization of the bowel. Ann. Surg. 158: 960, 1963.

13. Modlin, I. M., and Jaffe, B. M. Clinical usefulness of glucagon. Surgery 87: 470, 1980.

14. Ohnhaus, E. E. The effect of glucagon on the distribution of blood flow in the splanchnic area. Life Sci. 11, 1155, 1972.

15. Ottinger, L. W., and Austen, W. G. A study of 136 patients with mesenteric infarction. Surg. Gynecol. Ohstet. 124: 251, 1967.

16. Shapiro, D. M., Cronenwett, J. L., Lindenauer, S. M., Luce, J. L., and Stanley, J. C. Effects of glucagon and prostacyclin in acute occlusive and postocclusive canine mesenteric ischemia. $J$. Surg. Res. 36: 535, 1984.

17. Smitherman, T. C., Osborn, R. C., Jr., and Atkins, $J$. M. Cardiac dose response relationship for intravenously infused glucagon in normal intact dogs and men. Amer. Heart J. 96: 363, 1978. 